\title{
MULTI-COOPERATION IN CULTURAL HERITAGE CONSERVATION: THE CANGDONG PROJECT OF GUANGDONG PROVINCE
}

\author{
Jinhua Tan (Selia) a \\ a Department of Architecture \& Guangdong Qiaoxiang Cultural Research Center, Wuyi \\ University, Yingbin Road, Jiangmen, Guangdong, China-diaoloutan@qq.com \\ KEY WORDS: Multi-cooperation, Cultural Heritage Conservation, Cangdong Project, Adaptive Reuse. \\ Community Planning, Community Development
}

\begin{abstract}
:
In recent years, some workshops and research cases have arisen in China to seek for suitable ways for heritage conservation and development of historic villages. However, the issue of multi-cooperation has not been much mentioned in research works.

The case of Cangdong Project in Guangdong Province is a social enterprise. It is a center focusing on heritage education. It organizes tailor-made workshops for interested people from all over China and Hong Kong, Macao and overseas, including university courses for credits, summer/winter camps for primary and middle school students, as well as common people who are interested in heritage conservation. The purpose of the education center is to enhance heritage/cultural interest of the younger generations and common people, and try to work with local villagers to build a wealthy community. Nowadays, more and more villagers moved out for work and the countryside population in China is decreasing, this project also aims to create work opportunities for villagers through heritage conservation projects, so that the villagers can be willing to stay. The project focuses more in a sustainable way for community development.

It has been five years since the project was set up in Cangdong Village. The project team worked with villagers, city people, students, scholars, different levels of local governments, investors, Medias, charitable organizations, as well as the market of tourism. As such, a platform of multi-cooperation for the above parties has formed during the past five years. This paper takes the Project experience from 2010-2015 as the case to study multi-cooperation in the field of heritage conservation in China, as well as to discuss how to co-operate the subjective initiatives of different stokeholds.
\end{abstract}

\section{RESEARCH BACKGROUND}

With the rapid economic and tourism development in China, more and more historical sites/villages are exploited to be touristic destination. However, the development of these kind of villages are a bit out of control: local people and their lifestyle were not respected during the development, local culture/lifestyle was destroyed and villages/sites are far too commercial and touristic. Many people are bored with this kind of tourism. More and more people came to be aware of the importance of the real lifestyle of the place that they visit. They way of community planning that are prevalent in Japan and Taiwan is indeed something lacking in China. They try to reconstruct the beautiful and attractive hometown by the participation of local people who love their hometown and are enthusiastic in protecting their own heritages. Visitors are often touched by experiencing a place with real life. From the point of view of heritage conservation, only the real voices 
from the community can strike a chord in people's minds and that's the most meaningful protection.

The author always believe that the lack of heritage knowledge of common people and the lack of respect during the actual operation led by decisionmakers are the most key issues of heritage conservation in China. Moreover, public participation and community planning are essential for heritage sustainability.

In recent years, not a few research and analysis have been done on foreign experiences of village conservation and development cases, some scholars, individuals and NPOs even participated in this kind of countryside reconstruction activities. The concept of community planning is also mentioned in varying degrees. However, the author realized that few people pay attention to the multi-operation issue when operating heritage conservation projects, and more and more problems emerged.

In order to practice the feasibility of cooperation, the author establish a Cangdong Project in 2010 in Kaiping Country of Guangdong Province, with the financial help of her friend, Rocky Dang from Hong Kong who is also very keen on heritage conservation.

During the management of this project, the Cangdong Project people pay great attention to the cooperation with local people and villages, as well as other parties. The research topic of his paper is about how to balance the benefits of different stakeholders, how to maintain the relationship of different stakeholders, and how to ensure the sustainability of the village community.

\section{THE CANGDONG PROJECT}

\subsection{Basement of Multi-cooperation: Project} Purposes

The purpose of the Cangdong Project is to set up an example for local conservation and development of heritage through a real project. It takes the opportunity of heritage education to educate those who are interested in heritage conservation and cultural continuity, and at the same time, to revitalize some dying traditions. Furthermore, to help rebuild the cultural confidence of the local people, so that they can understand and participate in conservation works and share with visitors their life experience. The project also concerns to provide work opportunities to villagers to ensure their stay in the village and the sustainability of the community.

The purpose of the Cangdong Project is not just to conserve the beautiful historic buildings, but to help people understand the place, and the cultural identity of themselves and their lifestyle. The historical setting, the construction traditions, the fengshui beliefs, and the local lifestyle, especially the beliefs, folks arts, folk songs and craftsmanship, all should be respected.

The Cangdong Project has gone through the restoration and business operation in the past five years. During this period, the Project team keep working hard with different parties to balance the relationship, every party can find their own role in the Cangdong Project.

\subsection{Basement of Multi-cooperation: Working Principles}

The Cangdong Project team are with the academic background of heritage conservation and management, architecture, sociology etc. The difference are, all the staff have to work with different projects with different people from any other disceplines. They also have to understand the villagers and work with them. Villagers and craftsman are included in the management team of the project. Their comments and advice are respected too. Overseas professional support are welcomed but need to deal with local experience.

Teamwork, sharing, multi-cooperation, fair and just are the working principles in the Cangdong Project. To some degree, there is no "routine" work in office. The team members are required to have the ability to surpass their professional training, the ability of high cohesion, concentration and self-discipline. They have to learn both how to use his professional knowledge to make drawings and how to communicate with villagers. They also need to learn 
to avoid using professional terms when talking to villagers, they are encouraged to learn from villagers, to know the real wisdom from the local people and their actual needs.

In order to know more about the village and have more chance to talk with villagers. The major working team members put their office and live in Cangdong Village. In fact, "this kind of working mode does not mean you are away from the mainstream. The more globalization, the more we need to know the local place so as to make more significant dialogue with the world." Tinghua Li from the Yilan Branch of the National Taiwan University Building \& Planning Foundation said. Yuzhen Chen, who has 21-year experience and director of the Yilan Branch expressed the same concept, "to plough deep in your own place so as to integrate with the world". 2 The Yilan Experience thus attracts the world's attention, their "grass-root professional team" has offered help in quite some places in Taiwhan and China.

\subsection{Basement of Multi-cooperation: Management Concepts}

The Cangdong Project is a social enterprise for public good. The management strategy is to help enable hematopoietic function of this enterprise to take on full responsibility for the success. It won't rely on charitable donations and it won't be a burden of the local government or investors. As such, it is operated by the very experienced company from Hong Kong, the Intrinsic- Work \& Travel Company under the concept of social enterprise.

The main business scope of the Cangdong Project is Education - to organize training/workshops to promote traditional culture and heritage conservation, especially tailor-made workshops for primary and middle school students, as well as university students. It is also used as the off-campus outdoor education center of Wuyi University in Guangdong Province. Sometimes, there are also some training courses for interested adults. All and all, by the means of

${ }^{1}$ Collection of The Twenty Years of Work, National Taiwan University Building \& Planning Foundation, Pp.178. Taipei, 2013.

2 Ibid, p161. education, it mainly focuses on heritage. It actually creates a dialogue among the stakeholders for better understanding the history, culture, natural environment and the local lifestyle.

\subsection{Multi-cooperation: Operation Details}

The original purpose of the Cangdong Project is heritage conservation and promotion of heritage knowledge, but not community development. But in real practice, heritage conservation and community planning are connected, they two have no difference. In this point of view, the Cangdong Project is also regarded as community planning/development by some people. In fact, environmental protection, return to the earth and agriculture-oriented concepts are respected in all Cangdong project.

With the fact of decreasing population of Cangdong Village (resident population is 51), the Cangdong villagers are encouraged to bring villagers from surrounding villages, especially younger generations, as well as students from outside, to join the Cangdong project activities. It is hoped that those Cangdong villagers who moved out would sometimes come back to join some of the activities too. Nevertheless, all principles of world cultural heritage conservation are respected during the project, and the Cangdong community and villagers are the upmost consideration. Questions such as "Why conservation? What to protect? Who do we conserve for? And who do we develop for?" are the reminders during the Project. Therefore, the cooperation with villagers is on a "trust + respect + communication + understanding $=$ solution" basis.

The Cangdong Project has worked with many different cooperation parties, they are: local governments, institutions, villagers, overseas descendants, investors, visitors (students), Medias. Operation details are different according to different parties. Mutual respect and fairness and justice are always the basics.

\subsubsection{Local governments}

The Cangdong Project communicates with the relevant local governments during their planning, for 
example, the local management government, the People's Government of Tangkou Township, and the relevant Kaiping Bureau for Cultural Affairs.

The People's Government of Tangkou Township gives countenance to the Cangdong Project and gives their help within policy scope, they would send people to participate the Project meeting with villagers for support. The Kaiping Bureau for Cultural Affairs is also of help. They put Cangdong Village into their "cultural support plan" - offer free movie show and traditional performance when there are ceremonies in Cangdong.

The Cangdong Project offers professional help for the local governments. For example, to help establish the Conservation Guidelines of the Tangkou Tourism Development Committee; to give heritage and conservation lectures for the Kaiping Bureau for Tourism Management and the Kaiping Party School, as well as some professional associations, in the purpose of training relevant practitioner.

Local governments often uses the Cangdong Project as their example for investors. In August of 2015. A mini-documentary was filmed in Cangdong Village for commonweal publicity by the Kaiping Bureau for Cultural Affairs.

The Project also work with the Kaiping Bureau for Overseas Chinese Affairs, and provide free-charge guided tours and lectures whenever they have overseas people/descendants come. Promotion of hometown and traditional culture is one of the missions of the Cangdong Project.

\subsubsection{Institutions}

The Cangdong Project organizes tailor-made workshop for different institutions. Programs includes archeological program with Stanford University (USA), root-tracing program with the University of British Columbia (Canada), conservation workshop with the University of Hong Kong. The Cangdong Project also serves as the off-campus education center for the Department of Architecture, the local Wuyi University.

Middle schools student workshops are organized according to their needs, especially schools from
Hong Kong and Macao are very keen to have conservation workshops in Cangdong. There are outdoor education programs for overseas schools too.

\subsubsection{Villagers and overseas descendants}

Many Cangdong villagers supports the Project very much. Dr. Tse Tin Yao, a descendant from Hong Kong, donated money to restore the two ancestral halls; Mr. Xie Xuenuan, the chief of Cangdong, understands and supports the Cangdong Project very much and helps communicate between the Project and other villagers; Mrs Xie Xuenuan, a responsible lady who helps organize the vegetable gardens and kitchen work for the Project; Mr. Xie Haibo, a very skilled craftsman who is in charge of the conservation projects. Most hardworking women from the village would like to come work in the kitchen to cook food for students and visitors. The Candong Project would not be successful without their kind help.

The good relationship with the villagers is based on understanding and mutual respect. During conservation projects, the Project team communicate with villagers closely, their suggestions and advice are respected. Cangdong is their home, their heritage. They have the right to explain themselves. It is hoped that their ideas and feelings and memories are respected in conservation process. It is also believed that the villagers concern their heritage more than before with their participating in the education training courses. They have more confidence now and they are happy to join the activities organized for students, for example, BBQ and performances, they are happy to share local folk songs with students, for instance.

Villagers are happy to work in the kitchen, they cook food for visitors, sharing their cooking skill and others. For example, they help give cooking class for students; they help give constructions class for students, and some other folk arts.

Children of the villagers can participate in all training programs organized by the Cangdong Project without charge. Children gained from the programs not only the skills and the English knowledge, but also their understanding of their own culture is enhanced.

It is agreed that all the Project activities and 
workshops would not interfere the villagers' normal life. Workshops and courses would not be planned during their harvest time when they need the public space for drying grains; and would not be planned on any days when there are wedding and birthday banquets, nor on their traditional worshipping days.

\subsubsection{Visitors(students)}

Except for the workshops during summer and winter holidays, there are also weekend workshops and trainings for interested people. Students and many common people are interested in the ideas, concepts, and missions of the Project after participating in Cangdong workshops. They can experience traditional country culture, country life and enjoy the beautiful natural environment in Cangdong.

Visitors and students expressed their feelings in Cangdong "safe, relax, enjoyable, memorable" which almost disappear in city life. They learned heritage conservation knowledge in Cangdong and bring along with them, the seed of conservation, and that will be carried to many place wherever there are their footmarks.

The Cangdong Project operates free-charge docent serves twice a month. Visitors can book for guided tours on the two weekends.

\subsubsection{Investors}

Two investors who contributed to the Cangdong Project. Dr. Tse Tin Yao donated the money for the restoration of the two ancestral halls, Mr. Rocky Dang invests in the rest of the project and the on-going projects and business managements. Both of them are not strong business men who want to get rapid profit from the Project, and what's more, they are very understanding and caring for heritage conservation. They fully support the development ideas of the Cangdong Project and help to operate with the concept of social enterprise.

Mr. Rocky Dang pays great attention to the poor and old in the village, he often buys them necessary items such as medicines and also gives financial support. He supports the monthly magazine operated by the charitable committee of the Xie clan.

\subsubsection{Market}

There are two relevant markets, tourism and conservation.

China's tourism market is booming with the rapid economic development in the country. More and more tourist sites are destroyed by over-construction or commercial activities. People begin to seek for other healthier way of travel. Very few heritage sites in China can have the same pleasant environment as Cangdong has. This allows the potential heritage tourism for the Cangdong Project.

Chairman $\mathrm{Xi}$ Jinping promote heritage conservation heavily in China since 2015, in January he said: Cultural heritage is as valuable as life, protect it as if to project your life. As such conservation becomes popular in China and more and more younger generations realize the importance of heritage. The Cangdong Project thus becomes a place for interested people to come and share their conservation ideas and experience.

Workshops for students are all over China in these years, but the quality varies widely. Few of them have professional focus on traditional culture and heritage conservation. This allows the Project a market of outdoor education and professional workshops.

\subsubsection{Charitable Organizations}

The Cangdong Project widely work with other charitable organizations, to give them professional lectures and tours without charge. Heritage conservation groups and other charitable organizations in different areas of Guangdong were invited to Cangdong Village twice in the past two years.

\subsubsection{Medias}

The idea to work with Medias is for the promotion of heritage conservation. It is hope that the concept of heritage conservation will be widely spread with reports. The Cangdong Project had been reported by the Nanfang Daily, Yangcheng Everning Paper, Jiangmen Daily, as well as TV shows including the Guangdong Provincial TV Station, Zhejiang Provincial TV Station, Jiangmen City TV Station etc. 


\section{CONCLUSION: RESULT OF MULTI-COOPERATION - HARMONIOUS DEVELOPMENT}

In the past five years, the Cangdong Project team spent tremendous time to communicate with villagers, leading them to participate in reconstruct their community. More and more villagers who moved out would like to come back and have a look at the new scene of the village, and eventually in the Chinese New Year of 2015, more than 100 of them came back for the gathering on the seventh of January (lunar calendar).

Mr. Xie Xuenuan, the village chief said, "This has never ever happened before. A group of older people plan ancient instruments under the banyan tree, the lion-dance group play drums and lion dance in the playground, basketball them played basketball happily, the women team worked in the kitchen and did the worshipping at temple and the ancestral halls. During the meal, they had an agreement to collect donations to install street lamps for the public good, what's more, they set up that day the gathering day for reunion of Cangdong every year! Villagers send news of their activities and decisions to their fellow village friends in China, the US, Canada, Hong Kong and other countries.

This is the result of the Cangdong Project. Villagers learned from the programs organized by the Project inconsciently. The cultural confidence and local pride are back. The village traditions can be maintained in a more natural way through their own activities.

The villagers' positive participation in the local ritual during conservation projects, their worship in ancestral halls, wedding and birthday ceremonies is the origin of their village cohesion and concentration. This enhance the villagers' sense of belongs of their ancestral place, with more feelings and self-identity. The spirit and soul of the village can only be shown along with the people who live there.

Hsia Chu-joe, professor of National Taiwan University had once said, “ it (community development) actually changes people. A new society will be created during the community development process". ${ }^{3}$ This is very true for the case of Cangdong. Villagers who moved out came back to have wedding and birthday banquets are the evidences and the most important is, the tradition in the ancestral hall and under the banyan tree come back again.

This is the harmonious development that the author expects. Only by this way, can the goal and mission of the Cangdong Project achieved:

To keep the authentic village life and landscape without any marks that have nothing to do with village life;

It looks like trainees/visitors were coming to visit relatives and experience the simple traditional life, instead of learning heritage knowledge;

It looks like the villagers were not receiving visitors, but their relatives and friends from far away.
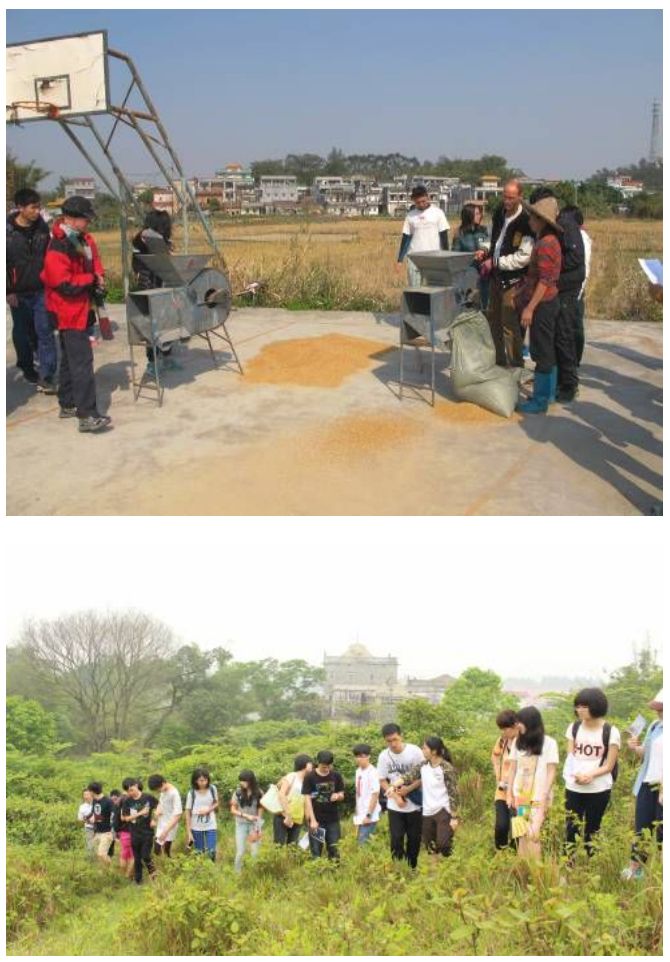

Student outdoor activities in the programs of the Project

\footnotetext{
${ }^{3}$ Preface, Rebuilt the Charming Hometown - Stories of the Rebirth of Traditional Communities in Japan. Chinese edition. Beijing, 2007
} 


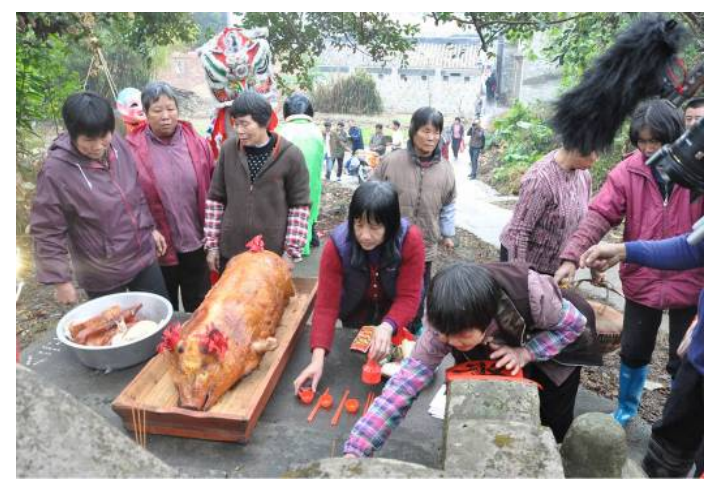

\section{REFERENCE}

Craig Langston, Francis K.W. Wong, Eddie C.M. Hui, Li-Yin Shen, 2007. Strategic assessment of building adaptive reuse opportunities in Hong Kong, Department of Building and Real Estate, The Hong Kong Polytechnic University, Kowloon, Hong Kong SAR, China, 2007.

ICOMOS Australia, 1999. The Burra Charter: The Australia ICOMOS Charter for the Conservation of Places of Cultural Significance (1999) by Australia ICOMOS

ICOMOS China. 2000. Principles for the Conservation of Heritage Sites in China, ICOMOS China. 2000.

ICOMOS , 1964. The Venice Charter 1964

(International Charter for the conservation and restoration of monuments and sites)

ICOMOS , 1999. Charter on the Built Vernacular Heritage, issued in October 1999.

ICOMOS, 2005. Xi'an declaration on the conservation of the setting of heritage structures, sites, and areas, 2005

ICOMOS , 2007. The ICOMOS Charter for the Interpretation and Presentation of Cultural Heritage,

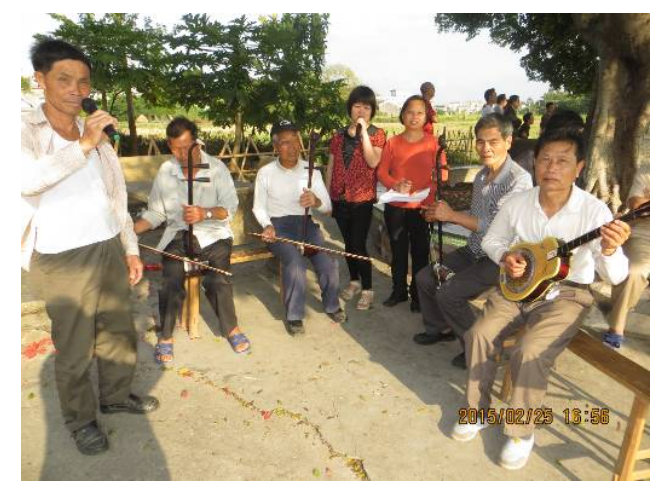

Country life in Cangdong Village remian the same as before

issued on 10 April 2007

ICOMOS, 2007. The Nara Document on Authenticity, issued in November 2007.

Kaiping Diaolou Research Department, 2006.

Kaiping Diaolou Application Dossier and

Management Plan

Landscape - -ICOMOS ISC Theory of Conservation. Prague, Czech Republic, 2010

Operational Guidelines for the Implementation of the World Heritage Convention, WHC. 2011, World Heritage Center, Paris

Meiyin Lin, 2001. Conservation and Development of Historic Streets and Villages (compiled by the Architectural Society of Japan). Translated by Lin Meiyin, 2001. Taichung. Preparation of the General Administration of Cultural Assets

Ping Zhuo - Collection of the Ten Years of Work of the National Taiwan University Building \& Planning Foundation, Taipei, 2000.

Qun Ce - Collection of the Twenty Years of Work of the National Taiwan University Building \& Planning Foundation, Taipei, 2013.

Values and Heritage Conservation Research Report, The Getty Conservation Institute, Los An-geles, The J. Paul Getty Trust, 2000. 
The International Archives of the Photogrammetry, Remote Sensing and Spatial Information Sciences, Volume XL-5/W7, 2015 25th International CIPA Symposium 2015, 31 August - 04 September 2015, Taipei, Taiwan

Yukio Nishimura, 2007. Rebuild the Charming

Hometown-Stories of the Rebirth of Traditional
Communities in Japan, Yukio NISHIMURA, Beijing, Chinese edition. 2007. 